\title{
Dağıtık Güç Üretiminin Şebekeye Entegrasyonu ve Olası Etkilerinin İncelenmesi
}

\author{
Tayfur Gökçek ${ }^{1 *}$, Yavuz Ateş ${ }^{1}$ \\ ${ }^{1}$ Yıldız Teknik Üniversitesi, Elektrik-Elektronik Fakültesi, Elektrik Mühendisliği Bölümü, İstanbul, Türkiye (ORCID: 0000-0003-1941-6914; 0000-0002-4168-0861 )
}

(İlk Geliş Tarihi 2 Şubat 2019 ve Kabul Tarihi 4 Mart 2019)

(DOI: $10.31590 /$ ejosat.521350)

ATIF/REFERENCE: Gökçek, T., \& Ateş, Y. (2019). Dağıtık Güç Üretiminin Şebekeye Entegrasyonu ve Olası Etkilerinin İncelenmesi. Avrupa Bilim ve Teknoloji Dergisi, (15), 216-228.

$\ddot{O} \mathbf{z}$

Günümüzde,gelişen teknoloji ile birlikte elektrik enerjisine olan talep de artmaktadır.Bu talebin karşılanması,konvansiyonel üretimin yetersiz kalmasından dolayı zorlu hale gelmiştir.Bunun sonucunda da dağıtık güç (DG) adı verilen,kısaca merkezi olmayan bir üretimin gerçekleştiği yeni tesis türleri yaygınlaşmaya başlamıştır.Fakat dağıtık güç üretiminin sağladı avantajların yanında,şebekeye entegrasyonunda birtakım dezavantajlar da mevcuttur.Tesis işletmesi açısından çeşitli analizler yapılarak bu dezavantajlar minimum seviyeye düşürülmelidir.Bu çalışmada IEEE 13 baralı test sistemindeki farklı güce sahip baralara,farklı tipte ve güçte bağlantılar gerçekleştirilerek ETAP programı üzerinde simülasyonları yapılmıştır.Simülasyon sonuçlarında dağıtık gücün bara gerilimlerine ve kısa devreye etkisi ile sistem kayıplarına katkısı incelenmiştir.Buna ek olarak enerjinin üretildiği yerde tüketiminin getirdiği avantajları kanıtlamak üzere ayrıca bir simülasyon çalışması daha yapılmıştır.Son olarak da elde edilen tüm entegrasyon senaryolarına göre optimal bağlantı noktası seçilerek,sistem dizaynında karşılaşılacak olası etkilerin minimum seviyeye indirildiği gözlemlenmiştir.

Anahtar Kelimeler: Dağıtık Güç, Şebeke Entegrasyonu, Yük Akışı Analizi, Kısa Devre Analizi.

\section{The Integration of Distributed Power Generation and Investigation Possible Impacts}

\begin{abstract}
The demand for electrical energy is increasing with the developing technology in the present. This demand has become difficult because of the insufficiency of conventional generation.As a result of this,new facility types that are named distributed power (DG) and are realized decentralized generation have began to become common. New plant types that are named distributed power (DG) and are realized decentralized generation, have began to become common.However, some disadvantages are available in the integration of the grid besides the advantages of distributed power generation. These disadvantages should decrease minimum level by carrying out various analysis in terms of plant operation.In this study, different types and power connections have been carried out to the busbars which have different power in the IEEE 13 bus test system and simulations are performed on the ETAP program.The effect of distributed power to bus voltage and short circuit and its contribution to system losses are investigated in the simulation results. In addition, a one more simulation study is carried out to prove the advantages of consumption where energy is produced. Finally, the optimal connection point is selected according to all the obtained integration scenarios and it is observed that the possible effects on the system designing are minimized.
\end{abstract}

Keywords: Distributed Power, Grid Integration, Power Flow Analysis, Short Circuit Analysis.

* Sorumlu Yazar: Yıldız Teknik Üniversitesi,Elektrik-Elektronik Fakültesi,Elektrik Mühendisliği Bölümü,İstanbul,Türkiye, ORCID: 0000-00031941-6914, gokcek.tayfur@gmail.com 


\section{Giriş}

Dağıtık güç üretimi literatürde;konvansiyonel üretim gibi merkezi olmayıp,iletim veya dağıtım hattı ile tüketici tarafında işletilebilen üretim olarak tanımlanmaktadır (Knyazkin ve Ackermann, 2003).

Dünya genelindeki enerji talebinin artması ile birlikte,konvansiyonel güç tesislerinin enerji verimliliği de azalmaktadır.Günümüzde,bu talebi karşılamak için dağıtık enerji adı altında; güneş enerjisi santralleri (GES),rüzgar enerjisi santralleri (RES),hidroelektrik enerji santralleri (HES),kombine 1sı ve güç santralleri (KIGS) ve yakıt hücreleri (YH) gibi dağıtık güç tesisleri yaygınlaşmıştır (Chowdhury vd., 2009). Fakat bu yaygınlaşma,birtakım sorunları da beraberinde getirmektedir.Literatürde çeşitli entegrasyon analizleri ile optimizasyon çalışmaları yapılarak bu sorunlar minimize edilmeye çalışılmaktadır.Özellikle de bağlantı bölgesi;gerilim ile kısa devre katkısını,sistem kayıplarını,sistemin güvenilirliğini ve kararlılığını oldukça değiştirebilmektedir (Dulău vd., 2016).

DG birimleri günümüzde çeşitli gruplara ayrılmış durumdadır.Öncelikle kullandıkları temel enerjiye göre yenilenebilir ve yenilenemez kaynaklar olarak ikiye ayrılırlar (Guan vd., 2009).RES,HES,YH ve GES yenilenebilir enerji kaynakları,KIGS ise yenilenemez enerji kaynakları grubuna girmektedir.İkinci olarak şebekeye bağlanma şekillerine göre gruplandırılırlar.Senkron generatörler (SG) ve çift beslemeli asenkron generatörler (ÇBAG) şebekeye doğrudan bağlanabilirken, fotovoltaikler (FV) ve YH'ler ise güç elektroniği arayüzüyle şebekeye bağlanabilirler (Afifi ve Darwish, 2016). Son olarak da güç üretimi ve tüketimine göre üç gruba ayrılmaktadırlar.Rüzgar türbinleri ve gaz türbinlerinde kullanılan SG'ler hem aktif güç hem de reaktif güç desteğinde bulunabilirler.Rüzgar türbinlerinde kullanılan diğer bir tür olan endüksiyon generatörleri (EG) aktif güç üretimi yapmasına karşın reaktif güç tüketimine ihtiyaç duyarlar.YH'ler ve FV'ler ise sisteme sadece aktif güç katkısında bulunurlar (Khan vd., 2015 ; Guan vd., 2009).

Birçok yazar ve (Ackermann vd., 2001 ) tarafından yapılan tanıma göre DG'ler kapasitelerine göre şu şekilde kategori edilebilmektedir:

Mikro ölçekli dağıtık güç kapasitesi: $\sim 1$ Watt $<5 \mathrm{~kW}$;

Düşük ölçekli dağıtık güç kapasitesi: $5 \mathrm{~kW}<5 \mathrm{MW}$;

Orta ölçekli dağıtık güç kapasitesi: $5 \mathrm{MW}<50 \mathrm{MW}$;

Geniş ölçekli dağıtık güç kapasitesi: $50 \mathrm{MW}<~-300 \mathrm{MW}$;

Bir elektrik sisteminde frekans ve gerilim parametrelerinin kontrolü oldukça önem arz etmektedir.Döner makinelerin senkronizasyonu için frekansın sürekliliği istenir.Fakat verimli çalışabilmeleri için harmoniklerin giderilerek frekansta saflığın sağlanması ve uygun değer aralığında tutulması gerekmektedir (Tarkan, 2016).Elektrik Şebeke Yönetmeliği'ne göre,sistemin 50 Hertz (Hz) olan nominal frekansı, TEİAŞ tarafından 49,8-50,2 Hz aralığında kontrol edilir.Gerilim profili açısından ise $66 \mathrm{kV}$ ve altındaki iletim sistemi için gerilim değişimi \%10’dur (EPDK, 2017).

DG ünitelerinden genelde gerilim ve frekans kontrolü beklenmemektedir.Fakat bağlantısı yapılan gücün kapasitesi arttıkça bu kontrol zorlaşmaktadır.Bu nedenle dağıtım hattına yapılan entegrasyonlarda gerilim ve frekans kontrolünün yapılması tavsiye edilmektedir.Ayrıca gerilim kontrolünün yapılması,reaktif kayıpların azaltılmasına imkan tanımaktadır (Çetinkaya ve Dumlu, 2013).

Yük tarafından çekilen reaktif güçler ve sistemdeki reaktif güç kayıpları,gerilim profilinde oldukça büyük bir etkiye sebep olurlar.IEEE $1547^{\mathrm{TM}}$ standardına göre DG ünitelerinin aktif olarak gerilim regülasyonuna katılmaları beklenmemektedir.Bu sebepten konvansiyonel senkron generatörler kontrol moduna göre reaktif gücü hem üretme hem de tüketme yeteneğine sahip olmasına rağmen sabit güç faktörü kontrol modu tercih edilir. Asenkron generatörler ise şebekeye direkt bağlandıklarında reaktif güç desteği yapamadıkları için konverter arayüzü ile sisteme entegre edilirler (Nuroğlu vd., 2008; Knyazkin vd., 2003).

Yüksek ölçekli DG bağlantılarında uzun hatlar kullanılması sonucunda gerilim regülasyonu bozulabilmektedir.Bunun sonucunda reaktif güç üretimi kısıtlanmak zorundadır.Gerilim regülasyonu;hat kesitlerinin arttırılması,kondansatör banklarının kullanılması,otomatik voltaj regülatörlerinin uyartım sistemi ve transformatörlerin kademe değişikliği ile yapılabilmektedir (Nuroğlu vd., 2008; Çetinkaya vd., 2003).

Sistemde oluşan kısa devre akımları istenmeyen bir durumdur.Arıza esnasında akacak yüksek değerli akımlar röle koordinasyonu sayesinde devre kesiciler tarafından sönümlendirilir.Arıza akımları simetrik ve asimetrik olmak üzere iki çeşittir.Simetrik arıza akımları en tehlikeli arıza akımları olarak kabul edilmektedir. Arıza noktasındaki kısa devre gücü arızadan önceki gerilim ile arızadan sonraki akımın çarpımı olarak :

$M V A_{K D}=\frac{\sqrt{3} \times U_{S} \times I_{K D}}{10^{6}}$

formülü ile hesaplanabilir.Aynı formül üzerinden arıza akımı ise:

$I_{K D}=\frac{M V A_{K D} \times 10^{6}}{\sqrt{3} \times U_{S}}$

olarak hesaplanabilir.Burada $U_{\mathrm{s}}(\mathrm{kV})$ ve $\mathrm{I}_{\mathrm{kd}}(\mathrm{kA})$ mertebesinde değerler olarak kabul edilmiştir.Eşitliklerden hareketle büyük kısa devre gücünün yüksek kısa devre akımlarına yol açabileceği söylenebilir.Bu durumlarda sistem ve ekipman korumaları için devre kesicilerin anma değerleri doğru seçilmelidir.Sisteme yapılan DG bağlantıları da kısa devre seviyelerini yükselterek koruma 
sorunlarına yol açabilmektedir.Kısa devre akımları, DG'nin bağlandığı konuma ve kapasitesine göre değişebilmektedir (Tarkan, 2016 ; Uqaili vd., 2014).Şekil 1'de DG’lerin kısa devreye katkısı şematik olarak gösterilmiştir.



Şekil 1. DG’lerin kısa devre katkısı

DG'lerin entegrasyonu sonucunda elde edilen avantajlardan birisi de aktif ve reaktif kayıpların azaltılmasıdır (Rangarajan vd., 2014).İletim ve dağıtım sistemleri aktif ve reaktif kayıplarda büyük bir rol oynamaktadır.Kayıpların değeri,hattan akan akıma ve hattın empedans büyüklüğüne bağlıdır.Bu sebepten kayıpları azaltmak için ya akım azaltılmalı ya da hattın empedans değeri düşürülmelidir.Bir sisteme DG entegrasyonu yapıldığında,şebekeden çekilecek olan güç azaldığından sistem kayıpları da azalacaktır (Chiradeja, 2005).Aktif ve reaktif güç kayıpları (3) ve (4) nolu eşitliklerden hesaplanabilmektedir.

$P_{A G}=3 \times R \times I^{2}$

$Q_{R G}=3 \times X \times I^{2}$

Entegrasyon yapılmadan önce sistem dizaynı doğru bir şekilde gerçekleştirilmelidir.Analizlerde;bağlantı yapılan bölge,bağlantısı yapılacak tesisin türü ve kapasitesi ile bağlantı şekli gibi etkenler optimum seçildiği taktirde dağıtık gücün meydana getireceği olası sorunlar minimum seviyeye indirgenebilmektedir (Khan vd., 2015).

Dünya literatüründe,DG’lerin şebeke entegrasyonundaki rolünü belirten çeşitli akademik çalışmalar yapılmıştır.Sonsuz şebekeden uç fiderlere doğru yapılan entegrasyonlarda gerilim profilindeki etki daha fazla olmaktadır.Ayrıca bölgedeki yük durumunun ve DG kapasitesinin gerilim regülasyonunda önemli bir rol oynadığı da bilinmektedir (Jones vd., 2008).Lokasyonun regülasyona olan katkısını inceleyen (Sun vd., 2009),yük akışı analizi sonrasında DG’lerin,bara gerilimlerini arttırıcı bir etkiye sahip olduğunu gözlemlemiştir.DG'lerin gerilim profilinde olduğu gibi kısa devre analizlerine olan etkisi;bağlantı lokasyonuna,kapasitesine ve tipine göre değişiklik göstermektedir (Uqaili vd., 2014). Kısa devre analizlerini inceleyen (Afifi vd., 2013) ; DG birimlerinin kısa devre akımlarını yükselttiğini,farklı bölge ve kapasite senaryoları ile değişken kısa devre katkılarının olduğunu gözlemlemiştir.Yine (Afifi vd., 2016) ayrı bir çalışmada farklı DG türlerinin sisteme olan etkisini incelemiştir.DG entegrasyonu ile birlikte artan kısa devre akımlarının koruma koordinasyonunu etkileyeceği göz önünde bulundurularak sistem güvenilirliği için kısa devre analizleri doğru bir şekilde yapılmalıdır (Vijeta vd., 2012). Son olarak, (Chiradeja vd., 2013) tarafindan,oldukça önem arz eden aktif ve reaktif güç kayıpları incelenmiş,entegrasyon bölgesindeki ve kapasitesindeki değişimlerin kayıpları nasıl etkilediği karşılaştırılmıştır.

Bu çalışmada,yukarıda belirtilen literatür bilgileri ve araştırmaları ışı̆̆ında,IEEE 13 baralı test sistemi üzerinde entegrasyon çalışmaları yapılmıştır.Uygulanan farklı senaryolar sonucunda sistem kayıplarını en aza indirecek bölge,bağlantısı yapılacak tesisin türü,kapasitesi ve bağlantı şekli belirlenmiştir.Ayrıca DG'lerin,tüketici gruplarının bulunduğu bölgelerdeki entegrasyonlarının sağladığı avantajları göstermek maksadıyla test sistemi üzerinde değişikliğe gidilerek ek analiz sonuçları gözlemlenmiştir.Çalışmadaki analiz aşamaları ve elde edilen sonuçlar sıralanmıştır:

- Talep yük doğrultusunda SG,ÇBAG ve FV tipi DG’ler,farklı kapasitelerde dizayn edilmiştir.

- Dizaynı gerçekleştirilen DG birimleri,gerilim kontrol modunda şebekeye entegre edilerek;sistemin gerilim profili,kısa devre akım seviyeleri ve kayıplar incelenmiştir. Sistem üzerinde değişikliğe gidilerek ek senaryo analizi gerçekleştirilmiştir.

- Analiz sonuçları doğrultusunda,aktif ve reaktif güç kayıpları açısından oldukça verimli değerler elde edilmiş olup,entegrasyon için uygun bara ve kapasite değerinin belirlenmesi sağlanmıştır.

- Enerjinin üretildiği bölgedeki tüketiminin,kayıpları çok daha azaltıcı bir etkiye sahip olduğu sonucuna varılarak,daha verimli bir şekilde entegrasyon yapılmasına katkı sağlanmıştır.

Yapılan çalışmanın ilk bölümünde literatür araştırması yapılarak dünya genelinde gerçekleştirilen çalışmalara yer verilmiştir.İkinci bölümde,şebeke modelinin ve dizayn edilen DG birimlerinin parametreleri paylaşılmış,üu̧üncü bölümde sistem analizi ve simülasyon sonuçlarına yer verilmiştir.Son bölümde ise elde edilen sonuçlar tartışılarak değerlendirmeler yapılmıştır. 


\section{Materyal ve Metot}

\subsection{Sistem Metodolojisi}

Çalışmanın ilk aşamasında,şekil 2'de belirtilen (Kersting, 2001) IEEE 13 baralı test sisteminin şebeke parametreleri göz önünde bulundurularak DG'lerin dizaynları modellenmiştir. Bu modeller,2 farklı kısa devre gücüne sahip olan 675 ve 680 nolu baralara 3 farklı güçte entegre edilerek, baralardaki gerilim profilleri,kısa devre akımları ve sistemdeki toplam kayıplar incelenmiştir.

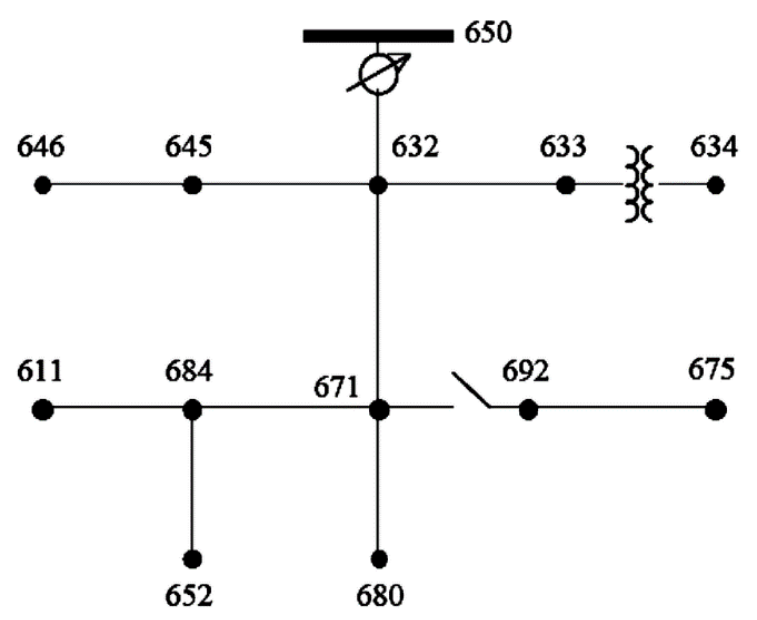

Şekil 2. IEEE 13 baralı test sistemi

\subsubsection{Test Sistemi Parametreleri}

Çalışmada referans alınan IEEE 13 baralı test sistemi dengesiz olup $(611,645,646,652,684)$ nolu baralar tek fazlı yükler içermektedir.Test sisteminde yer alan ana güç şebekesinin ve entegrasyonu yapılan baraların parametreleri listelenmiştir:

- Sonsuz şebeke,4.16 kV değerindeki 632 nolu baraya bağlı olup $71.072 \mathrm{MVA}$ üç faz kısa devre gücüne sahiptir.X/R oranı ise 2.744 olarak belirlenmiştir.

- Sistemde $60 \mathrm{~Hz}$ frekans ve ANSI standartları kullanılmıştır.

- Sistemin 675 nolu barası 4,16 kV değerinde olup,971 kVA değerinde yük ve 600 kvar değerinde kapasitör grubu içermektedir.Güç şebekesine $2500 \mathrm{ft}$. uzaklıkta bulunmaktadır.

- Sistemin 680 nolu barası güç şebekesine $3000 \mathrm{ft}$. ile en uzak mesafede bulunan baradır.Bara $4.16 \mathrm{kV}$ değerinde olup herhangi bir tüketici grubu içermemektedir.

\subsubsection{DG Kapasitelerinin Belirlenmesi}

DG’lerin kapasiteleri belirlenmeden önce ETAP üzerinde IEEE 13 baralı sistemin entegrasyonsuz senaryosu simüle edilmiştir.Sistemin kayıpları ve bağlı olan kapasitörler de dikkate alındığında ana şebekeden 3.515 MW aktif güç,1.530 Mvar reaktif güç çekilmektedir.Toplamda da (5) nolu eşitlikten :

$S_{T}=\sqrt{P^{2}+Q^{2}}$

3.833 MVA değerinde bir görünür gücün çekildiği hesaplanabilmektedir.Bağlanacak DG’lerin kapasiteleri (6) nolu eşitlikten yararlanılarak :

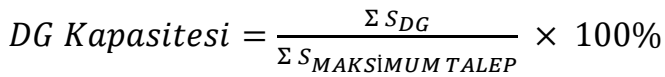

0.766 MVA (20\%) , 1.533 MVA (40\%) , 2.3 MVA (60\%) , 3.066 MVA (80\%) olarak 4 ayrı kapasite belirlenmiştir.Ünitelerin elektriki güçleri 0.85 güç faktörü uyarınca (7) nolu eşitlikten:

$P_{T}=S_{T} \times \cos \theta$

$0.65 \mathrm{MW}(20 \%), 1.303 \mathrm{MW}(40 \%), 1.955 \mathrm{MW}(60 \%)$, $2.606 \mathrm{MW}(80 \%)$ olarak hesaplanmaktadır.

\subsubsection{DG Dizayn Parametreleri}

$\mathrm{Bu}$ bölümde analiz çalışmasında kullanılan dizel SG,rüzgar türbini modeli ÇBAG ve FV sistem modellerinin parametreleri paylaşılmıştır.Gereken sayıda ünite bağlantısı yapılarak 0.65 MW, 1.303 MW, 1.955 MW ve 2.606 MW kurulu güç değerleri elde 
edilmiştir.Tüm DG birimleri 0.4/4.16 kV dönüştürme oranına sahip transformatörler üzerinden 500 m. uzunluğunda XLPE tipi kablo ile,ilgili baralara entegre edilmiştir. Gerilim kontrol modunda çalıştırılan DG birimlerinin dizayn parametreleri listelenmiştir:

- FV dizaynında,Kyocera markasının $232 \mathrm{~W}$ gücündeki KD235GX-LPB modeli kullanılmıştır. $36.56 \mathrm{~V}_{\mathrm{oc}}$ ve $8.48 \mathrm{I}_{\mathrm{sc}}$ değerlerine sahip olan panelin,istenen kurulu güç elde edilecek şekilde seri ve paralel bağlantıları gerçekleştirilmiştir.Modellemede $1000 \mathrm{~W} / \mathrm{m}^{2}$ 1şınım değeri ile $25{ }^{\circ} \mathrm{C}$ ortam sıcaklığı baz alınmıştır.Panel grupları; \%100 verime ve 0.85 güç faktörüne sahip,sırasıyla $765 \mathrm{kVA}, 1533 \mathrm{kVA}, 2300 \mathrm{kVA}$ ve $3066 \mathrm{kVA}$ gücündeki inverter gruplarına bağlanmiştır.

- ÇBAG dizaynında,tip 3 rüzgar türbini gerilim kontrol modunda çalıştırılmıştır.Önceki bölümde belirtilen kurulu güçlerde dizayn edilen generatörler; 0.85 güç faktörüne ve \%100 verime sahip olup 4 kutupludur.Modellemede $10 \mathrm{~m} / \mathrm{s}$ ortalama rüzgar hızı baz alınmıştır.Ünitenin aktif güç,reaktif güç ve kanat açısı kontrol parametreleri ETAP programının belirlediği değerler olarak kabul edilmiştir.

- Dizel SG dizaynı,ÇBAG parametreleri ile aynı değerdedir.Generatörler,0.85 güç faktörüne ve \%100 verime sahip olup 4 kutupludur.Reaktif güç kapasitesi ile generatör empedans değerleri,yine ETAP programı tarafından hesaplanan ve belirlenen değerler olarak kabul edilmiştir.Generatörün kontrol mekanizmaları,sabit uyarmalı otomatik voltaj regülatörü ve DT tipi governör olarak belirlenmiştir.

\section{Araştırma Sonuçları ve Tartışma}

\subsection{Sistem Analizi ve Simülasyon Sonuçları}

Çalışmanın bu bölümünde IEEE 13 baralı test sistemine,önceki bölümde dizaynları paylaşılan DG'lerin,farklı senaryolar altında entegrasyonları yapılarak ETAP programı üzerinde analiz sonuçları elde edilmiştir.Sonuçlar sırasıyla;gerilim profili analizi,kısa devre analizi ve sistem kayıpları analizi başlıkları altında paylaşılmıştır.Ayrıca sistem üzerinde değişikliğe gidilerek ek simülasyon analizi yapılmıştır.DG'lerin kısa devre gücü yüksek olan 632 ve 633 nolu baralardaki etkileri çok az olup kayıpları arttırıcı bir davranışa sahip olduğundan bu çalışmada analizlerine yer verilmemiştir. Belirlenen 4 ayrı kapasitenin entegrasyonları şekil 3’teki gibi gerçekleştirilerek sistem üzerinde farklı etkilere sahip olduğu gözlenmiştir.

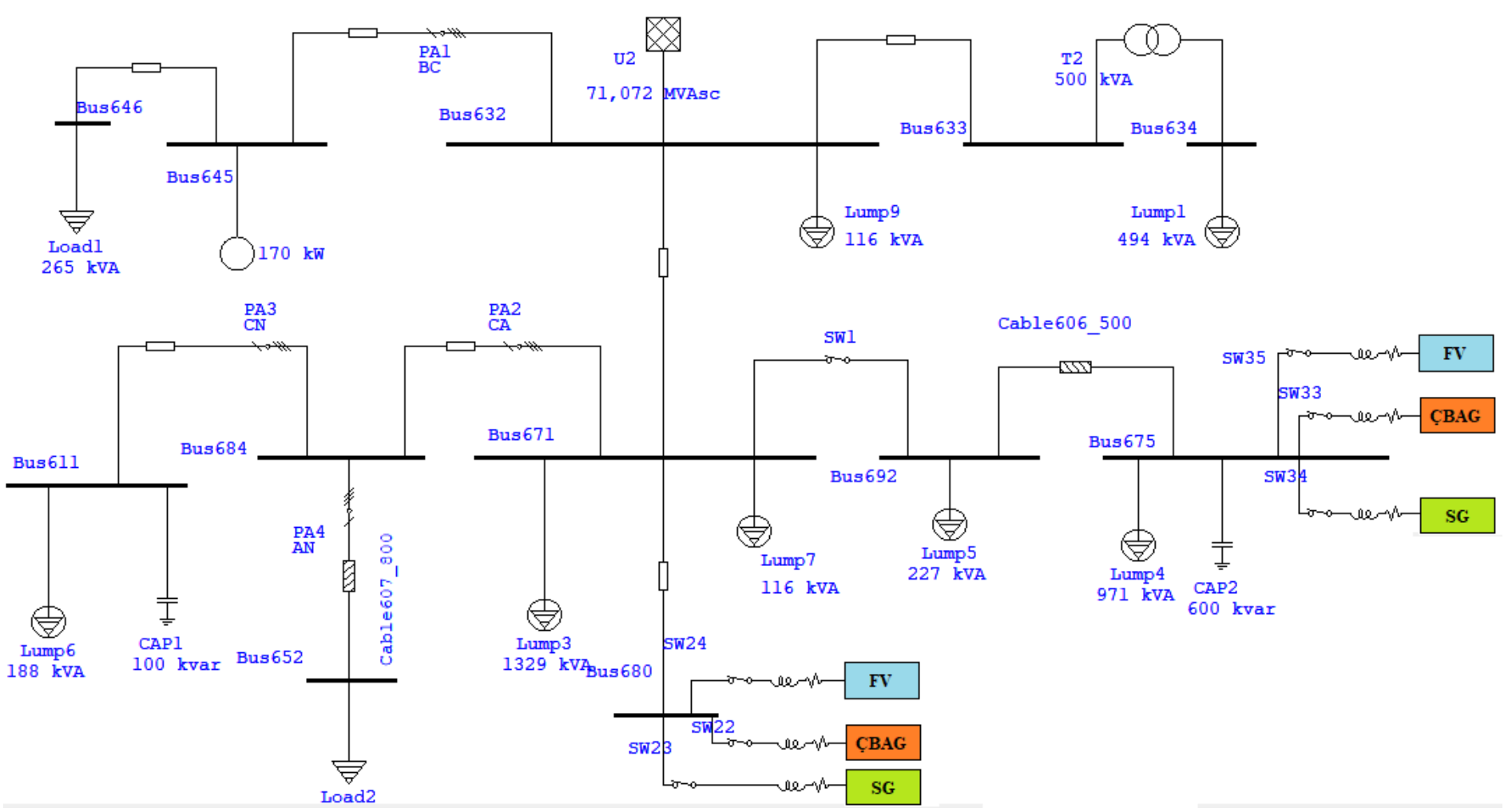

Şekil 3. DG entegrasyonu tek hat şeması 


\subsubsection{Gerilim Profili Analizi}

Bu bölümde DG’lerin 675 ve 680 nolu baralara entegrasyonu sonrasında bara gerilimlerindeki değișimler incelenmiștir.Tüm DG üniteleri gerilim kontrol modunda sisteme bağlanarak yük akışı analizi gerçekleştirilmiştir.Analiz sonuçlarına göre tüm DG'lerin aynı etkiyi yaptığı ve bara gerilimini artırıcı yönde bir etkisi olduğu görülmüştür.Şekil 4 ve şekil 5 ’te de artan kapasitelerle birlikte gerilim seviyesinin de arttı̆̆ gözlemlenmiştir.

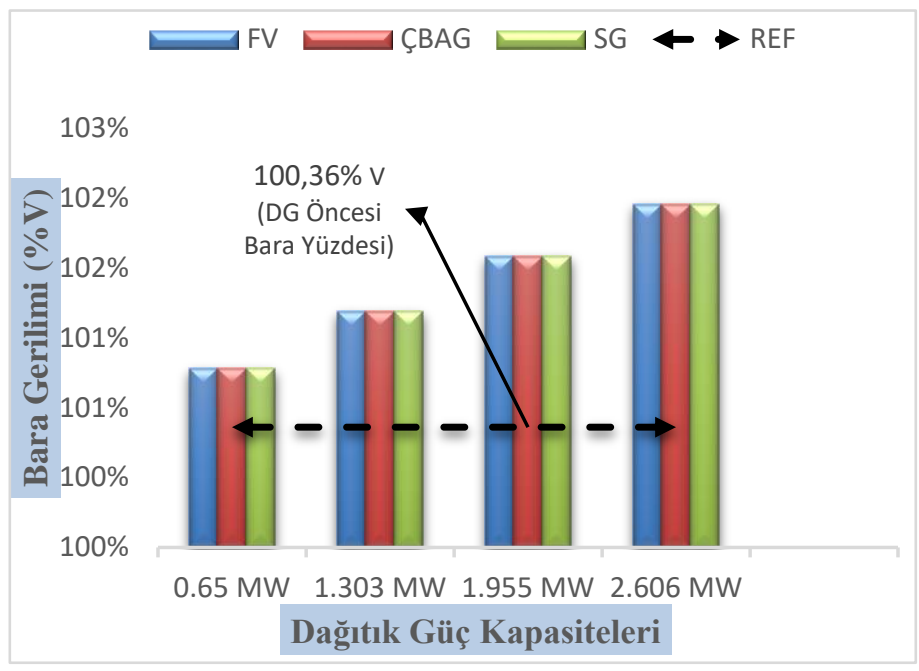

Şekil 4. 675 nolu baranın gerilim profili

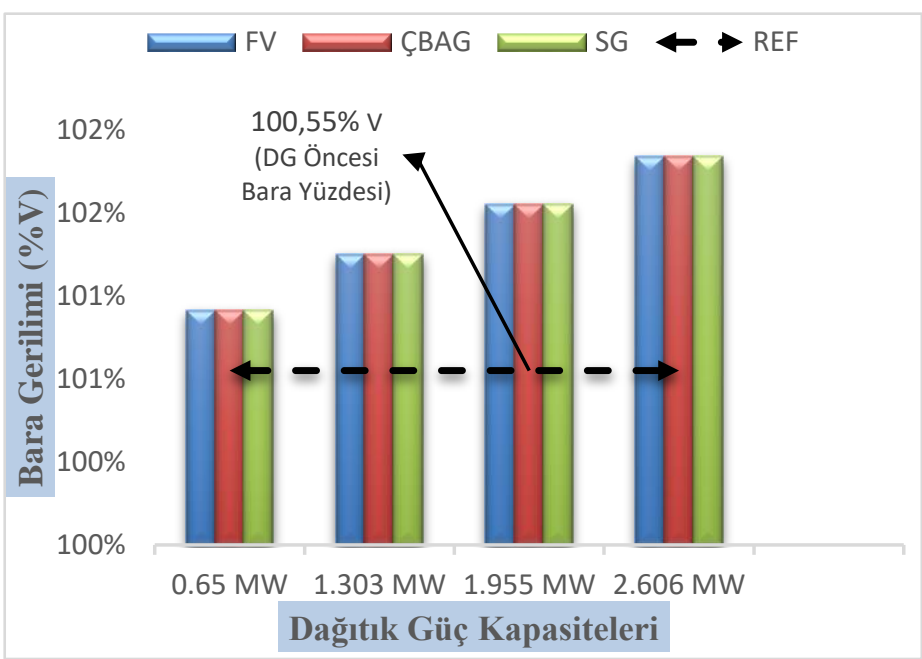

Şekil 5. 680 nolu baranın gerilim profili

675 nolu barada entegrasyon öncesi bara gerilim değeri \%100.36 iken, entegrasyon sonrasında bara gerilim değeri 0.65 MW'lik kapasitede \%100.78, 1.303 MW'lik kapasitede \%101.19, 1.955 MW'lik kapasitede \%101.58 ve 2.606 MW'lik kapasitede \%101.95 değerine yükselmiştir.Aynı kapasitedeki tüm DG birimlerinin gerilim kontrol modunda regülasyona yardımcı olarak eşit değerde katkı verdikleri gözlemlenmiştir.

680 nolu baraya yapılan entegrasyonda 675 nolu baradaki etkilerin aynıları gözlemlenmiştir.Entegrasyon öncesi bara gerilim değeri \%100.55 iken, entegrasyon sonrasında bara gerilim değeri 0.65 MW'lik kapasitede \%100.91, 1.303 MW'lik kapasitede \%101.25 , 1.955 MW'lik kapasitede \%101.55 ve 2.606 MW'lik kapasitede \%101.84 değerine yükselmiştir. Her iki baranın gerilim profili karşılaştırmalı olarak tablo 1'de gösterilmişstir.

Tablo 1. DG sonrası bara gerilimlerindeki değişim

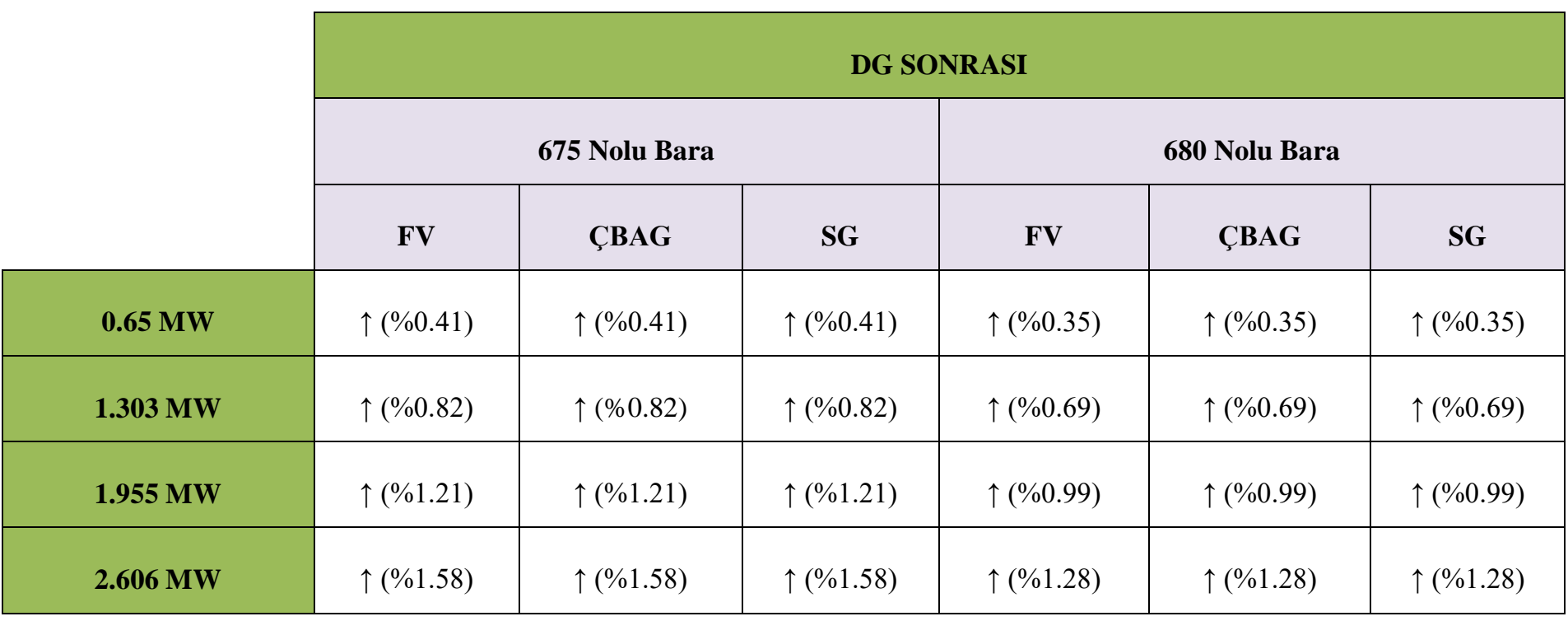


Literatür bilgilerine göre 680 nolu bara entegrasyonunda daha olumlu sonuçların elde edilmesi beklenmekteydi.Fakat Tablo 1'deki verilere göre 680 nolu baraya yapılan entegrasyonun bara gerilimine daha az etki ettiği görülmektedir.Bunun da,680 nolu barada herhangi bir tüketicinin olmamasından kaynaklandığı düşünülmektedir.Ayrıca aynı elektriki güce sahip DG birimlerinin aynı oranda regülasyona yardımcı olduğu da görülmüştür.

\subsubsection{Kısa Devre Analizi}

Bu bölümde 675 ve 680 nolu baralara entegrasyonda DG’lerin kısa devre katkıları incelenmiştir.Simülasyon için kısa devre analizi gerçekleştirilmiştir.Analiz sonuçlarına göre sisteme tam kontrollü konverter ile bağlanan FV’lerin en az kısa devre katkısına sahip olduğu,ÇBAG ve SG bağlantılarında ise FV'ye göre daha fazla ve yaklaşık olarak aynı oranda katkı sağlandığı görülmüştür.Gerilim profilinde olduğu gibi kapasitelerle birlikte kısa devre akımlarının da arttığı gözlemlenmiştir.Şekil 6 ve şekil 7'de DG’lerin kısa devre katkıları gösterilmektedir.

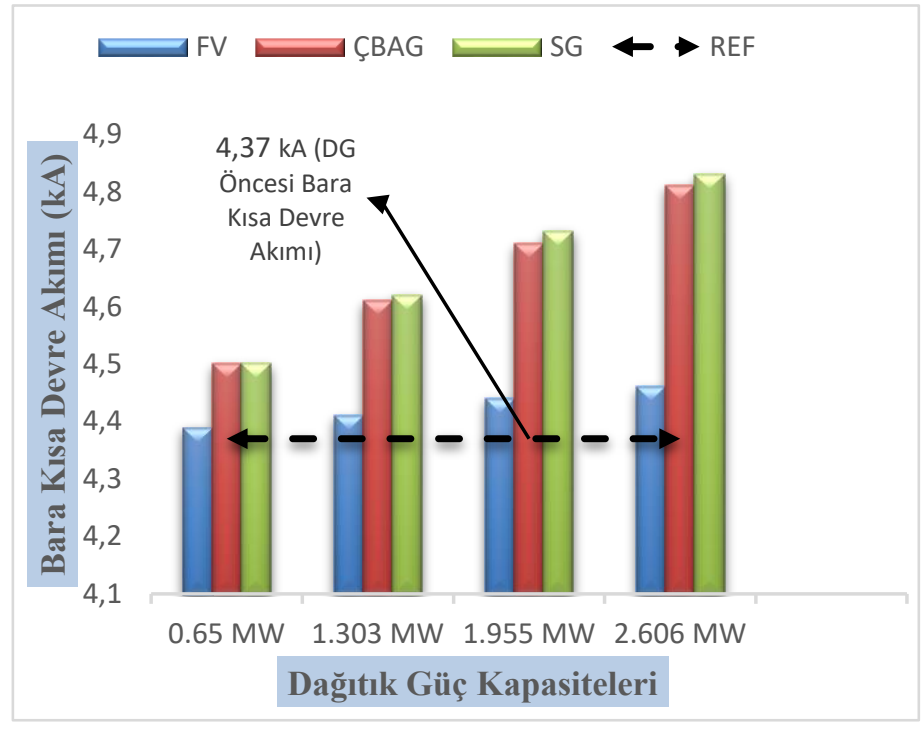

Şekil 6. 675 nolu baranın kısa devre akımı

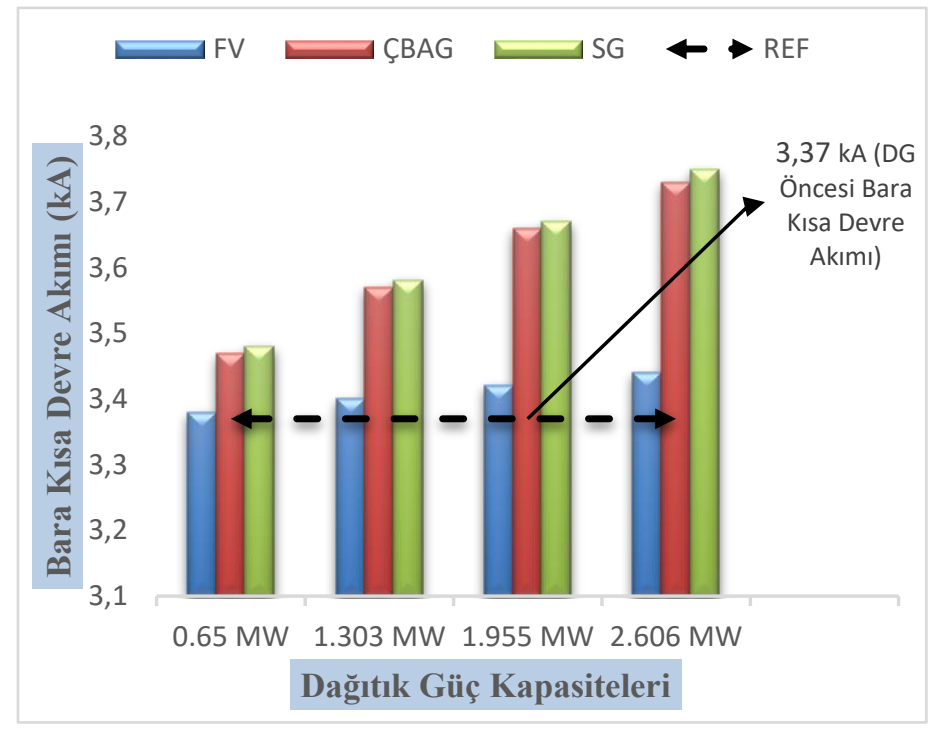

Şekil 7. 680 nolu baranın kısa devre akımı

675 nolu barada entegrasyon öncesi kısa devre akımı 4.37 kA iken, entegrasyon sonrasında kısa devre akımı, 0.65 MW'lik kapasitede FV katkısı ile 4.39 kA, ÇBAG ve SG katkısı ile 4.5 kA; 1.303 MW'lik kapasitede FV katkısı ile 4.41 kA, ÇBAG katkısı ile $4.61 \mathrm{kA}$ ve SG katkısı ile 4.62 kA, 1.955 MW'lik kapasitede FV katkısı ile 4.44 kA, ÇBAG katkısı ile 4.71 kA ve SG katkısı ile $4.73 \mathrm{kA}$ ve 2.606 MW'lik kapasitede FV katkısı ile $4.46 \mathrm{kA}$, ÇBAG katkısı ile $4.81 \mathrm{kA}$ ve SG katkısı ile 4.83 kA değerine yükselmiştir.

680 nolu barada entegrasyon öncesi kısa devre akımı 3.37 kA iken, entegrasyon sonrasında kısa devre akımı 0.65 MW'lik kapasitede FV katkısı ile 3.38 kA, ÇBAG katkısı ile 3.47 kA ve SG katkısı ile 3.48 kA; 1.303 MW'lik kapasitede FV katkısı ile 3.4 kA, ÇBAG katkısı ile 3.57 kA ve SG katkısı ile 3.58 kA, 1.955 MW'lik kapasitede FV katkısı ile 3.42 kA, ÇBAG katkısı ile 3.66 kA ve SG katkısı ile 3.67 kA ve 2.606 MW'lik kapasitede FV katkısı ile 3.44 kA, ÇBAG katkısı ile 3.73 kA ve SG katkısı ile 3.75 kA değerine yükselmiştir.Her iki baranın kısa devre akımlarındaki değişim karşılaştırmalı olarak tablo 2'de gösterilmiştir. 
Tablo 2. DG sonrası bara kısa devre akımlarındaki değişim

\begin{tabular}{|c|c|c|c|c|c|c|}
\hline & \multicolumn{6}{|c|}{ DG SONRASI } \\
\hline & \multicolumn{3}{|c|}{675 Nolu Bara } & \multicolumn{3}{|c|}{680 Nolu Bara } \\
\hline & FV & ÇBAG & SG & FV & ÇBAG & SG \\
\hline 0.65 MW & $\uparrow(\% 0.45)$ & $\uparrow(\% 2.97)$ & $\uparrow(\% 2.97)$ & $\uparrow(\% 0.29)$ & $\uparrow(\% 2.96)$ & $\uparrow(\% 3.26)$ \\
\hline $1.303 \mathrm{MW}$ & $\uparrow(\% 0.91)$ & $\uparrow(\% 5.49)$ & $\uparrow(\% 5.72)$ & $\uparrow(\% 0.89)$ & $\uparrow(\% 5.93)$ & $\uparrow(\% 6.23)$ \\
\hline $1.955 \mathrm{MW}$ & $\uparrow(\% 1.6)$ & $\uparrow(\% 7.78)$ & $\uparrow(\% 8.23)$ & $\uparrow(\% 1.48)$ & $\uparrow(\% 8.6)$ & $\uparrow(\% 8.9)$ \\
\hline $2.606 \mathrm{MW}$ & $\uparrow(\% 2.05)$ & $\uparrow(\% 10.06)$ & $\uparrow(\% 10.52)$ & $\uparrow(\% 2.07)$ & $\uparrow(\% 10.68)$ & $\uparrow(\% 11.27)$ \\
\hline
\end{tabular}

Tablo 2'deki verilere göre sisteme tam kontrollü konverter ile bağlanan FV'lerin her iki lokasyonda da kısa devre akımlarını oldukça engelleyici bir yapıya sahip olduğu görülmektedir.ÇBAG ve SG bağlantıları,FV bağlantılara göre daha fazla kısa devre akımı katkısına sahip olmakla birlikte 675 nolu baraya daha az kısa devre katkı sağlamışlardır.

\subsubsection{Sistem Kayıpları Analizi}

$\mathrm{Bu}$ bölümde 675 ve 680 nolu baralara entegrasyonda DG'lerin sistem kayıplarındaki davranışları incelenmiştir. Analiz sonuçlarına göre ÇBAG ve SG'nin FV'ye göre aktif ve reaktif kayıpları azaltıcı etkisinin daha fazla olduğu gözlemlenmiştir.Bağlantı lokasyonuna ve kapasitesine göre sistem kayıpları da değişiklik göstermektedir.Şekil 8 ve şekil 9'da sistemin aktif güç kayıpları gösterilmektedir.

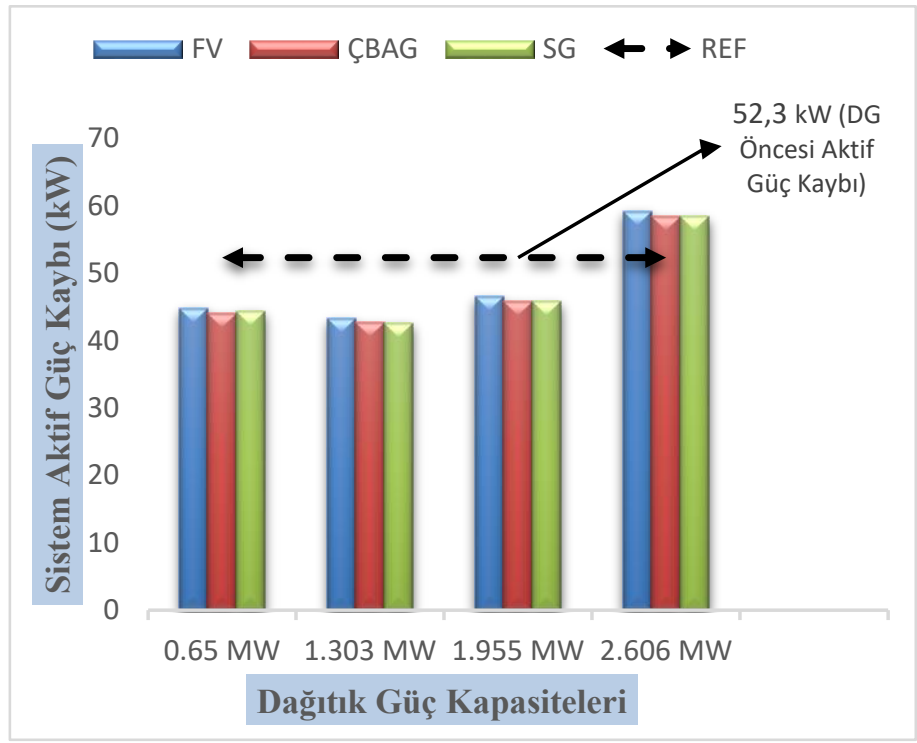

Şekil 8. 675 nolu baraya DG entegrasyonu sonrası sistemin aktif kayıları

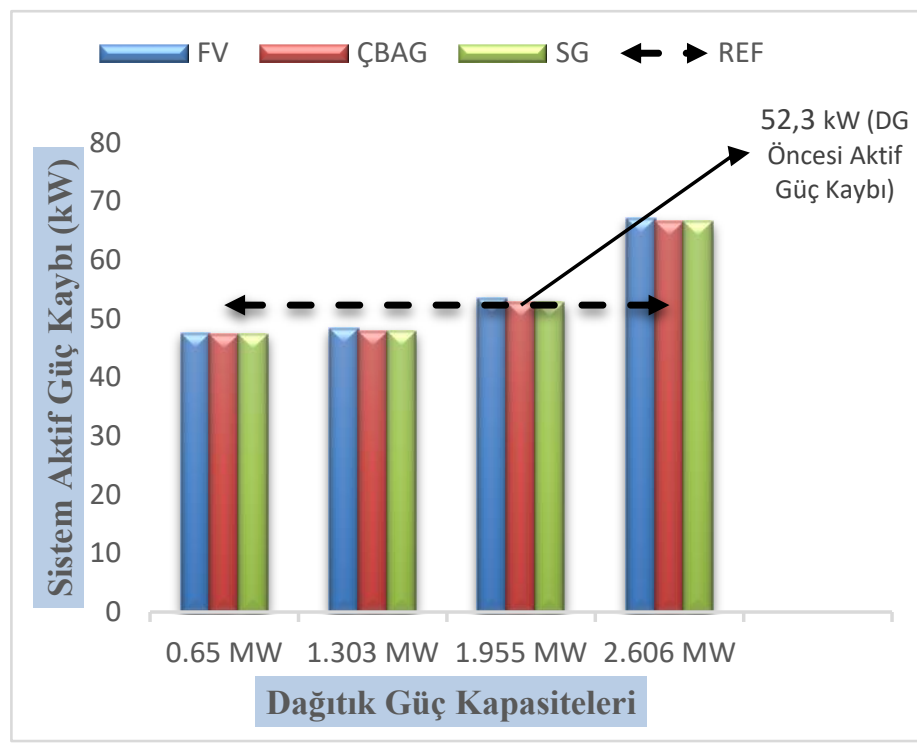

Şekil 9. 680 nolu baraya DG entegrasyonu sonrası sistemin aktif kayıpları

675 nolu barada entegrasyon öncesi sistem aktif güç kaybı $52 \mathrm{~kW}$ iken, entegrasyon sonrasında aktif güç kaybı 0.65 MW'lik kapasitede FV katkısı ile 44.7 kW, ÇBAG katkısı ile 44 kW ve SG katkısı ile 44.4 kW; 1.303 MW'lik kapasitede FV katkısı ile 43.3 kW, ÇBAG katkısı ile 42.7 kW ve SG katkısı ile 42.6 kW, 1.955 MW'lik kapasitede FV katkısı ile 46.6 kW, ÇBAG ve SG katkısı ile $45.8 \mathrm{~kW}$ değerine düşürülmüştür. 2.606 MW'lik kapasitede ise FV katkısı ile $59.1 \mathrm{~kW}$, ÇBAG ve SG katkısı ile 58.4 kW değerine yükselmiştir. \%80 oranındaki DG kapasitesinin sistem üzerinde negatif bir etki yarattığı açıkça görülmektedir. 
680 nolu baraya entegrasyon sonrasında aktif güç kaybı, 0.65 MW'lik kapasitede FV katkısı ile 47.5 kW, ÇBAG ve SG katkısı ile $47.3 \mathrm{~kW}$; 1.303 MW'lik kapasitede FV katkısı ile $48.3 \mathrm{~kW}$, ÇBAG ve SG katkısı ile 47.8 kW değerine düşürülmüştür. 1.955 MW'lik kapasitede FV katkısı ile 53.4 kW, ÇBAG ve SG katkısı ile 52.7 kW; 2.606 MW'lik kapasitede ise FV katkısı ile 67 kW, ÇBAG ve SG katkısı ile $66.5 \mathrm{~kW}$ değerine yükselmiştir.675 nolu bara entegrasyonlarına göre sistem kayıpları üzerindeki etkinin daha düşük olduğu gözlenmiştir. \%60 ve \%80 oranındaki DG kapasitesinin sistem üzerinde kayıpları arttırıcı bir etkiye sahip olduğu görülmektedir. Tablo 3 ’te aktif güç kayıplarının karşılaştırmalı olarak analizi yapılmıştır.

Tablo 3. DG sonrası aktif güç kayıplarındaki değişim

\begin{tabular}{|c|c|c|c|c|c|c|}
\hline & \multicolumn{6}{|c|}{ DG SONRASI } \\
\hline & \multicolumn{3}{|c|}{675 Nolu Bara } & \multicolumn{3}{|c|}{680 Nolu Bara } \\
\hline & FV & ÇBAG & SG & FV & ÇBAG & SG \\
\hline $0.65 \mathrm{MW}$ & $\downarrow(\% 14.53)$ & $\downarrow(\% 15.86)$ & $\downarrow(\% 15.1)$ & $\downarrow(\% 9.17)$ & $\downarrow(\% 9.56)$ & $\downarrow(\% 9.56)$ \\
\hline $1.303 \mathrm{MW}$ & $\downarrow(\% 17.2)$ & $\downarrow(\% 18.35)$ & $\downarrow(\% 18.54)$ & $\downarrow(\% 7.64)$ & $\downarrow(\% 8.6)$ & $\downarrow(\% 8.6)$ \\
\hline 1.955 MW & $\downarrow(\% 10.89)$ & $\downarrow(\% 12.42)$ & $\downarrow(\% 12.42)$ & $\uparrow(\% 2.1)$ & $\uparrow(\% 0.76)$ & $\uparrow(\% 0.76)$ \\
\hline $2.606 \mathrm{MW}$ & $\uparrow(\% 13)$ & $\uparrow(\% 11.66)$ & $\uparrow(\% 11.66)$ & $\uparrow(\% 28.1)$ & $\uparrow(\% 27.15)$ & $\uparrow(\% 27.15)$ \\
\hline
\end{tabular}

Analiz verilerine göre 675 nolu baraya yapılan entegrasyon \%60`lık DG bağlantısına kadar aktif kayıpları düşürmektedir.Aynı elektriki yapıya sahip elektrik makinalarının FV'ye göre daha etkili olduğu görülmektedir.Şekil 10 ve şekil 11'de entegrasyon sonrasında sistemin reaktif güç kayıplarındaki değişim verilmiştir.

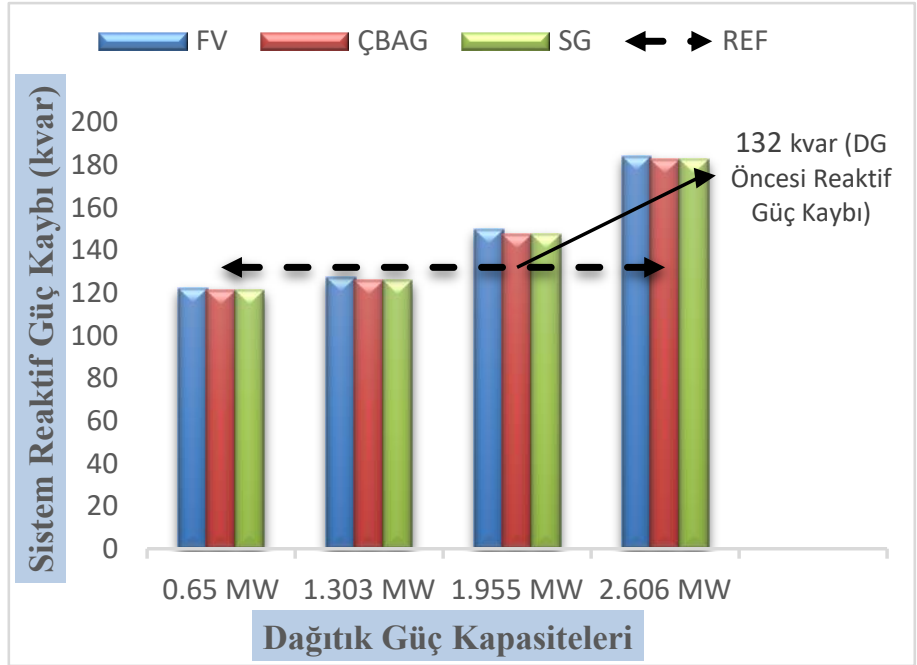

Şekil 10. 675 nolu baraya DG entegrasyonu sonrası sistemin reaktif kayıpları

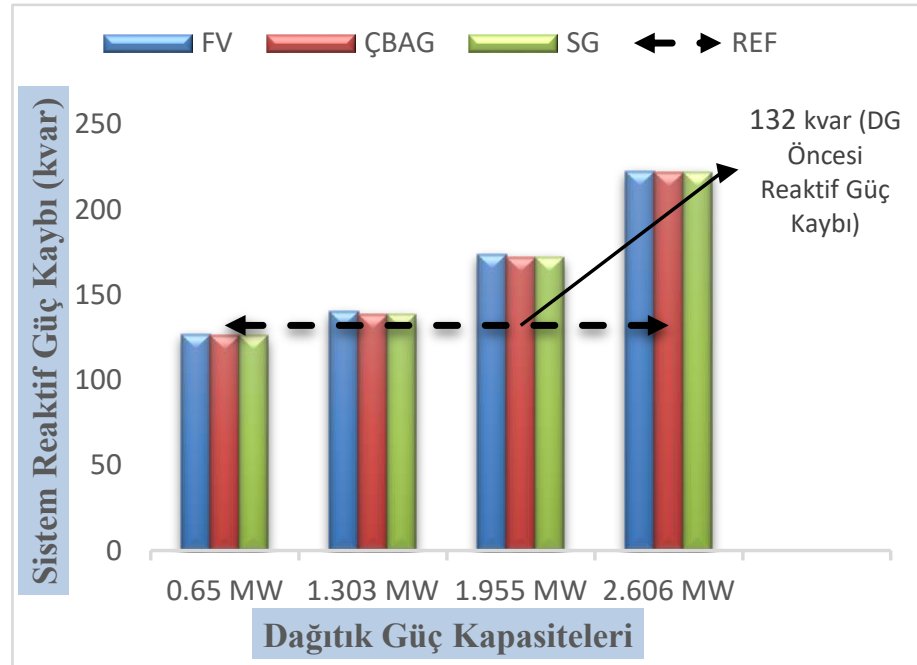

Şekil 11. 680 nolu baraya DG entegrasyonu sonrası sistemin reaktif kayıpları

Sistem reaktif güç kaybı açısından incelendiğinde entegrasyon öncesi kayıp 132 kvar iken,entegrasyon sonrasında reaktif güç kaybı 0.65 MW'lik kapasitede FV katkısı ile 122.1 kvar, ÇBAG ve SG katkısı ile 121 kvar; 1.303 MW'lik kapasitede FV katkısı ile 127.4 kvar, ÇBAG ve SG katkısı ile 125.6 kvar değerine düşürülmüştür. 1.955 MW'lik kapasitede FV katkısı ile 149,5 kvar,ÇBAG ve SG katkısı ile 147.1 kvar; 2.606 MW'lik kapasitede ise FV katkısı ile 184 kvar, ÇBAG ve SG katkısı ile 182,4 kvar değerine yükselmiştir. 
680 nolu bara entegrasyonu ile birlikte reaktif güç kaybı 0.65 MW'lik kapasitede FV katkısı ile 126.6 kvar, ÇBAG ve SG katkısı ile 125.8 kvar değerine düşürülmüştür. 1.303 MW'lik kapasitede FV katkısı ile 140 kvar, ÇBAG ve SG katkısı ile 138.5 kvar; 1.955 MW'lik kapasitede FV katkısı ile 173.4 kvar,ÇBAG ve SG katkısı ile 171.6 kvar; 2.606 MW'lik kapasitede ise FV katkısı ile 222.5 kvar, ÇBAG ve SG katkısı ile 221.7 kvar değerine yükselmiştir.680 nolu bara entegrasyonunda aktif güç kayıplarında olduğu gibi reaktif güç kayıplarında da olumsuz etkiler gözlemlenmiştir. Tablo 4’te aktif güç kayıplarının karşılaştırmalı olarak analizi yapılmıştır.

Tablo 4. DG sonrası reaktif güç kayıplarındaki değişim

\begin{tabular}{|c|c|c|c|c|c|c|}
\hline & \multicolumn{6}{|c|}{ DG SONRASI } \\
\hline & \multicolumn{3}{|c|}{675 Nolu Bara } & \multicolumn{3}{|c|}{680 Nolu Bara } \\
\hline & FV & ÇBAG & SG & FV & ÇBAG & SG \\
\hline $0.65 \mathrm{MW}$ & $\downarrow(\% 7.5)$ & $\downarrow(\% 8.33)$ & $\downarrow(\% 8.33)$ & $\downarrow(\% 4.09)$ & $\downarrow(\% 4.69)$ & $\downarrow(\% 4.69)$ \\
\hline $1.303 \mathrm{MW}$ & $\downarrow(\% 3.48)$ & $\downarrow(\% 4.84)$ & $\downarrow(\% 4.84)$ & $\uparrow(\% 6.06)$ & $\uparrow(\% 4.92)$ & $\uparrow(\% 4.92)$ \\
\hline 1.955 MW & $\uparrow(\% 13.25)$ & $\uparrow(\% 11.43)$ & $\uparrow(\% 11.43)$ & $\uparrow(\% 31.36)$ & $\uparrow(\% 30)$ & $\uparrow(\% 30)$ \\
\hline $2.606 \mathrm{MW}$ & $\uparrow(\% 39.39)$ & $\uparrow(\% 38.18)$ & $\uparrow(\% 38.18)$ & $\uparrow(\% 68.56)$ & $\uparrow(\% 67.95)$ & $\uparrow(\% 67.95)$ \\
\hline
\end{tabular}

Tablo 4'teki verilere göre 680 nolu baraya yapılan bağlantı,kayıplar açısından kısıtlanmaktadır.\%20 ve \%40 kapasiteli bağlantılar 675 nolu entegrasyonda kayıpları azaltırken bu değer 680 nolu barada \%20 kapasiteli bağlantıya düşmektedir. Normal şartlarda en uzak bara olan 680 nolu baraya yapılan entegrasyonlar sonucunda sistem kayıplarının en aza indirilmesi beklenmekteydi.Fakat test sisteminde 680 nolu barada herhangi bir tüketicinin bulunmaması beklenen sonucu vermemektedir.Entegrasyonlarda tüketici etkisinin gösterilmesi için bir sonraki bölümde ek bir simülasyon çalışması yapılmıştır.

\subsubsection{Ek Senaryo Analizi}

Bu bölümde DG entegrasyonlarında,bağlantı yapılan bölgedeki tüketici varlığının kayıplar üzerindeki etkisi incelenmiştir.Test sistemi üzerindeki 675 nolu baraya bağlı olan 971 kVA'lık yük ile 600 kvar değerindeki kapasitör,675 nolu baradan kaldırılmadan 680 nolu baraya da eklenerek aktif ve reaktif güç kayıpları gözlemlenmiştir.DG öncesi kayıplar tablo 5 'te gösterilmektedir.

Tablo 5. Yeni senaryoda DG öncesi sistem kayıları

\begin{tabular}{|c|c|}
\cline { 2 - 2 } \multicolumn{1}{c|}{} & DG ÖNCESI \\
\hline $\begin{array}{c}\text { Aktif } \\
\text { Kayıplar }\end{array}$ & $91.7 \mathrm{~kW}$ \\
\hline $\begin{array}{c}\text { Reaktif } \\
\text { Kayıplar }\end{array}$ & $256.9 \mathrm{kvar}$ \\
\hline
\end{tabular}

Sistemdeki yeni yük değişikliği sonrasında sistemin aktif güç kaybı 91.7 kW ve reaktif güç kaybı 256.9 kvar olarak hesaplanmıştır.Tüm DG birimlerinin yeni senaryoda kayıplara olan etkisi tablo 6 ve tablo 7'de gösterilmektedir. 
Avrupa Bilim ve Teknoloji Dergisi

Tablo 6. Yeni senaryoda DG sonrası aktif güç kayıplarındaki değişim

\begin{tabular}{|c|c|c|c|c|c|c|}
\hline & \multicolumn{6}{|c|}{ DG SONRASI } \\
\hline & \multicolumn{3}{|c|}{675 Nolu Bara } & \multicolumn{3}{|c|}{680 Nolu Bara } \\
\hline & FV & ÇBAG & SG & FV & ÇBAG & SG \\
\hline \multirow[t]{2}{*}{$0.65 \mathrm{MW}$} & $79.2 \mathrm{~kW}$ & $78.2 \mathrm{~kW}$ & $78.2 \mathrm{~kW}$ & $79.7 \mathrm{~kW}$ & $78.6 \mathrm{~kW}$ & $78.6 \mathrm{~kW}$ \\
\hline & $\downarrow(\% 13.63)$ & $\downarrow(\% 14.72)$ & $\downarrow(\% 14.72)$ & $\downarrow(\% 13.08)$ & $\downarrow(\% 14.28)$ & $\downarrow(\% 14.28)$ \\
\hline \multirow[t]{2}{*}{$1.303 \mathrm{MW}$} & $72.8 \mathrm{~kW}$ & $71.1 \mathrm{~kW}$ & $71.1 \mathrm{~kW}$ & $73.3 \mathrm{~kW}$ & $71.5 \mathrm{~kW}$ & $71.5 \mathrm{~kW}$ \\
\hline & $\downarrow(\% 20.61)$ & $\downarrow(\% 22.46)$ & $\downarrow(\% 22.46)$ & $\downarrow(\% 20.06)$ & $\downarrow(\% 22.02)$ & $\downarrow(\% 22.02)$ \\
\hline \multirow[t]{2}{*}{$1.955 \mathrm{MW}$} & $71.4 \mathrm{~kW}$ & $69.2 \mathrm{~kW}$ & $69.2 \mathrm{~kW}$ & $71.2 \mathrm{~kW}$ & $69 \mathrm{~kW}$ & $69 \mathrm{~kW}$ \\
\hline & $\downarrow(\% 22.13)$ & $\downarrow(\% 24.53)$ & $\downarrow(\% 24.53)$ & $\downarrow(\% 22.35)$ & $\downarrow(\% 24.75)$ & $\downarrow(\% 24.75)$ \\
\hline \multirow[t]{2}{*}{$2.606 \mathrm{MW}$} & $79.2 \mathrm{~kW}$ & $76.9 \mathrm{~kW}$ & $76.9 \mathrm{~kW}$ & $78.1 \mathrm{~kW}$ & $75.7 \mathrm{~kW}$ & $75.7 \mathrm{~kW}$ \\
\hline & $\downarrow(\% 13.63)$ & $\downarrow(\% 16.13)$ & $\downarrow(\% 16.13)$ & $\downarrow(\% 14.83)$ & $\downarrow(\% 17.44)$ & $\downarrow(\% 17.44)$ \\
\hline
\end{tabular}

Tablo 7. Yeni senaryoda DG sonrası reaktif güç kayıplarındaki değişim

\begin{tabular}{|c|c|c|c|c|c|c|}
\hline & \multicolumn{6}{|c|}{ DG SONRASI } \\
\hline & \multicolumn{3}{|c|}{675 Nolu Bara } & \multicolumn{3}{|c|}{680 Nolu Bara } \\
\hline & FV & ÇBAG & SG & FV & ÇBAG & SG \\
\hline 0.65 MW & $\begin{array}{l}230.8 \mathrm{kvar} \\
\downarrow(\% 10.15)\end{array}$ & $\begin{array}{c}227.6 \mathrm{kvar} \\
\downarrow(\% 11.4)\end{array}$ & $\begin{array}{l}227.6 \text { kvar } \\
\downarrow(\% 11.4)\end{array}$ & $\begin{array}{l}227.7 \text { kvar } \\
\downarrow(\% 11.36)\end{array}$ & $\begin{array}{l}224.2 \text { kvar } \\
\downarrow(\% 12.72)\end{array}$ & $\begin{array}{l}224.2 \mathrm{kvar} \\
\downarrow(\% 12.72)\end{array}$ \\
\hline $1.303 \mathrm{MW}$ & $\begin{array}{l}220.2 \mathrm{kvar} \\
\downarrow(\% 14.28)\end{array}$ & $\begin{array}{l}215 \text { kvar } \\
\downarrow(\% 16.3)\end{array}$ & $\begin{array}{l}215 \mathrm{kvar} \\
\downarrow(\% 16.3)\end{array}$ & $\begin{array}{l}217.6 \mathrm{kvar} \\
\downarrow(\% 15.29)\end{array}$ & $\begin{array}{l}211.9 \text { kvar } \\
\downarrow(\% 17.51)\end{array}$ & $\begin{array}{l}211.9 \mathrm{kvar} \\
\downarrow(\% 17.51)\end{array}$ \\
\hline $1.955 \mathrm{MW}$ & $\begin{array}{l}226.7 \text { kvar } \\
\downarrow(\% 11.75)\end{array}$ & $\begin{array}{l}220.1 \mathrm{kvar} \\
\downarrow(\% 14.32)\end{array}$ & $\begin{array}{l}220.1 \text { kvar } \\
\downarrow(\% 14.32)\end{array}$ & $\begin{array}{l}228.2 \text { kvar } \\
\downarrow(\% 11.17)\end{array}$ & $\begin{array}{l}221.2 \text { kvar } \\
\downarrow(\% 13.89)\end{array}$ & $\begin{array}{l}221.2 \mathrm{kvar} \\
\downarrow(\% 13.89)\end{array}$ \\
\hline $2.606 \mathrm{MW}$ & $\begin{array}{l}246.3 \mathrm{kvar} \\
\downarrow(\% 4.12)\end{array}$ & $\begin{array}{l}239.6 \text { kvar } \\
\downarrow(\% 6.73)\end{array}$ & $\begin{array}{c}239.6 \mathrm{kvar} \\
\downarrow(\% 6.73)\end{array}$ & $\begin{array}{c}255.2 \mathrm{kvar} \\
\downarrow(\% 0.66)\end{array}$ & $\begin{array}{l}248.3 \mathrm{kvar} \\
\downarrow(\% 3.34)\end{array}$ & $\begin{array}{l}248.3 \mathrm{kvar} \\
\downarrow(\% 3.34)\end{array}$ \\
\hline
\end{tabular}


Tablo 6 ve tablo 7'deki verilere göre \% 20 ve \% 40 kapasiteli DG bağlantıları birbirine en yakın ve en olumlu sonuçları vermektedir.Yeni senaryo öncesinde 680 nolu baraya yapılan entegrasyonlarda kayıpları arttırıcı sonuçlar var iken,yeni senaryo sonrasında bu olumsuz durum kaldırılmıştır.Önceki durumda aktif kayıplar en iyi senaryoda \% 19 kadar azaltılırken,yeni senaryoda bu değer \%25 değerlerine kadar yükselmiştir.Reaktif güç kayıpları ise,önceki durumda en iyi senaryoda \%8 azaltılırken,yeni senaryoda bu değer \%17.5 değerine kadar yükselmiştir.DG üniteleri arasında da döner makinelerin solar sisteme göre daha avantajlı olduğu görülmektedir.

\section{Sonuç}

Yapılan çalışma kapsamında,öncelikle farklı tipteki DG birimleri ETAP yazılımı üzerinde modellenmiştir.FV,ÇBAG ve SG kaynakları farklı güçlerde seçilerek,675 ve 680 nolu baralara entegrasyonu yapılmıştır.Çalışmada IEEE'nin 13 Baralı Test Modeli referans olarak kullanılmıştır.0.65 MW,1.303 MW ,1.955 MW ve 2.606 MW güçlerindeki DG birimlerinin bağlantısı yapılarak ilk olarak baralardaki gerilim profili incelenmiştir.Sistemin en uzak barası olan 680 nolu barada tüketici bulunması durumunda gerilim regülasyonunun daha iyi sağlandığı ve gerilim kontrol modunda çalışan tüm DG’lerin aynı değerde katkı sağladığı gözlemlenmiştir.

Kısa devre çalışmasında,şebekeye inverter üzerinden bağlı olan FV sistemin kısa devre akımına katkısının yok denebilecek kadar az seviye olduğu gözlemlenmiştir.ÇBAG ve SG'nin kısa devre katkılarının FV'ye göre daha fazla ve birbirine yakın olduğu sonucuna varılmıştır.Bağlantı noktası açısından ise, 680 nolu bara entegrasyonunda kısa devre katkılarının daha fazla olduğu görülmektedir.

Sistem kayıplar açısından değerlendirildiğinde,ilk senaryoda 680 nolu bara entegrasyonu oldukça olumsuz sonuçlara yol açmaktadır.675 nolu bara entegrasyonunda en olumlu senaryoda aktif kayıplar \% 19,reaktif kayıplar da \% 9 oranında azaltılırken 680 nolu bara entegrasyonunda bu değerler sırasıyla $\% 10$ ve $\% 5$ değerlerinde kalmıştır.Sistemde yapılan yük değişiminden sonra ise 680 nolu bara entegrasyonunda görülen olumsuzluklar kalkmıştır.En iyi senaryoda aktif kayıplardaki azalma \% 10 'dan \% 25 'e , reaktif kayıplardaki azalma da \%5'ten \% 18 değerlerine yükselerek oldukça avantajlı bir durum elde edilmiştir.Bu analiz sonrasında önemli derecede tüketicinin bulunduğu en uzak bölgeye yapılan DG entegrasyonlarının daha avantajlı sonuçlar verdiği anlaşılmaktadır.

Çalışma sonuçlarından da görüldüğü üzere DG’lerin şebeke bağlantısında,gerilim regülasyonunda zorluk,kısa devre katkılarında ve kayıplarda artış gibi birtakım sorunlara rastlanılmaktadır.Fakat çalışmada yapılan analizler ile bu sorunların önüne geçilebilir.Özellikle de ÇBAG ve SG bağlantılarının FV'de olduğu gibi konverter arayüzüyle sisteme bağlantısıyla çok daha verimli sonuçlar alınabilir.Ayrıca bağlantı yapılacak bölgedeki tüketim değerleri sistem kayıplarına yüksek derecede etki ettiğinden analizlerde göz önünde bulundurulması büyük önem arz etmektedir.Gerçekleştirilen çalışma ile optimizasyon çalışmalarında en verimli sonuçların elde edilmesi sağlanmıştır.Gelecek çalışmalarda,kompleks yapılardaki hibrit DG üniteleri sayesinde sistem verimliliğinin maksimum seviyeye çıkarılması hedeflenmektedir. 


\section{Kaynakça}

Ackermann, T., Andresson, G. ve Söder, L., 2001. Distributed generation: a definition, Electric Power Systems Research, Vol.57,Issue.3,pp. 195-204.

Afifi, S. N., Wang, H., Taylor G. A., Irving M. R.,2013. Impact of DFIG Wind Turbines on Short Circuit Levels in Distribution Networks using ETAP, 48th International Universities' Power Engineering Conference (UPEC), IEEE, 2-5 Sept., 2013, Dublin,Ireland.

Afifi, S. N. ve Darwish, M. K.,2016. Impact of PV/Wind/Diesel Hybrid System on the Distribution Networks, International Conference on Renewable Energies and Power Quality (ICREPQ'16), RE\&PQJ, 4-6 May., 2016, Madrid,Spain.

Chiradeja, P., Benefit of Distributed Generation: A Line Loss Reduction Analysis. 2005 IEEE/PES Transmission \& Distribution Conference \& Exposition: Asia and Pacific, IEEE, 18-18 Aug., 2005,Dalian, China.

Chiradeja, P. ve Ngaopitakkul A.,2013. The impacts of electrical power losses due to distributed generation integration to distribution system, International Conference on Electrical Machines and Systems (ICEMS),IEEE, 26-29 Oct., 2013,Busan, South Korea.

Chowdhury, S., Chowdhury, S. P. ve Crossley, P., 2009. Microgrids and Active Distribution Networks, London,UK.

Çetinkaya, H. B. ve Dumlu, F. (2013). http://www.emo.org.tr/ekler/76bfae53cf6ecbd_ek.pdf adresinden alındı.

Dulău, L. I., Abrudean, M. ve Bică, D., 2016. Optimal Location of a Distributed Generator for Power Losses, ScienceDirect, Vol.22, pp. 734-739.

Enerji Piyasası Düzenleme Kurumu (EPDK), 2017. Elektrik Şebeke Yönetmeliği.

Guan, F. H., Zhao, D. M., Zhang, X., Zhan, B. T. ve Liu, Z.. Research on Distributed Generation Technologies and its impacts on Power System, 2009 International Conference on Sustainable Power Generation and Supply, IEEE, 6-7 April, 2009, Nanjing, China.

Jones, G. W. ve Chowdhury, B. H., 2008. Distribution System Operation and Planning in the Presence of Distributed Generation Technology, Transmission and Distribution Conference and Exposition (PES), IEEE, 21-24 Apr., 2008, Chicago, IL, USA.

Kersting, W. H., 2001.Radial distribution test feeders, IEEE Power Engineering Society Winter Meeting. Conference Proceedings (Cat. No.01CH37194), IEEE, 28 Jan.-1 Feb., 2001, Columbus, OH, USA.

Khan, Z. W. ve Khan, S., 2015. Analyzing The Impacts of Distributed Generation on Power Losses and Voltage Profile, International Conference on Emerging Technologies (ICET), IEEE, 19-20 Dec., 2015, Peshawar, Pakistan.

Knyazkin, V. ve Ackermann, T., 2003. Interaction Between The Distributed Generation and The Distribution Network:Operation,Control and Stability Aspects, 17th International Conference on Electricity Distribution (CIRED), ResearchGate, 12-15 May., 2003, Barcelona,Spain.

Nuroğlu, F. M. ve Arsoy, A. B., 2008. Voltage Profile and Short Circuit Analysis in Distribution Systems with DG, Electrical Power \& Energy Conference, IEEE, 6-7 Oct., 2008, Vancouver, BC, Canada.

Rangarajan, S. S., Sreejith, S. ve Nigam, S., 2014. Effect of Distributed Generation on Line Losses and Network Resonances, International Conference on Advances in Electrical Engineering (ICAEE), IEEE, 9-11 Jan., 2014, Vellore, India.

Sun, Q., Li, Z. ve Zhang, H., 2009. Impact of Distributed Generation on Voltage Profile in Distribution System, International Joint Conference on Computational Sciences and Optimization, IEEE, 24-26 Apr., 2009, Sanya, Hainan, China.

Tarkan, N., Eylül, 2016. Elektrik Enerji Sistemlerinin Analiz ve Optimizasyonuna Dayalı İşletilmesi, İstanbul, İTÜ Vakfi.

Uqaili, M. A., Sahito, A. A., Halepoto, I. A., Memon, Z. A. ve Dars, S. B., 2014. Impact of Distributed Generation on Network Short Circuit Level, 4th International Conference on Wireless Communications, Vehicular Technology, Information Theory and Aerospace \& Electronic Systems (VITAE), IEEE, 11-14 May., 2014, Aalborg, Denmark.

Vijeta, K. ve Sarma, D. V. S. S. S., 2012. Protection of Distributed Generation Connected Distribution System, International Conference on Advances in Power Conversion and Energy Technologies (APCET), IEEE, 2-4 Aug., 2012, Mylavaram, Andhra Pradesh, India. 